1. MBBS, FCPS (Anesthesia) Professor Anesthesia University Medical and Dental College Faisalabad.

2. MBBS, FCPS

Professor Surgery University Medical and Dental College Faisalabad.

3. MBBS, FCPS

Professor Surgery

University Medical and Dental College Faisalabad.

4. MBBS, FCPS (Surgery)

Assistant Professor Surgery University Medical and Dental College Faisalabad.

5. MBBS, FCPS (Surgery)

Senior Registrar Surgery

Allied Hospital, Faisalabad.

6. MBBS, FCPS

Assistant Professor Surgery Sargodha Medical College Sargodha,

Correspondence Address:

Dr. Nadia Bano

Department of Anesthesia

University Medical and Dental College

Faisalabad.

drnadiabano@gmail.com

Article received on:

20/08/2020

Accepted for publication:

$12 / 02 / 2021$

\section{Comparative study of midline versus paramedian approach of spinal block in elderly.}

\begin{abstract}
Nadia Bano', Nazim Hayat ${ }^{2}$, Saira Saleem ${ }^{3}$, Farhan Javed ${ }^{4}$, Ayesha Rehman $^{5}$, Khalid Mahmood ${ }^{6}$
ABSTRACT... Objective: To compare the efficacy of paramedian and midline approach for spinal block in elderly, in terms of success rate and number of attempts required by either approach. Study Design: Randomized Controlled Trial. Setting: Department of Anaesthesia, Madina Teaching Hospital Faisalabad. Period: January 2018 to December 2019. Material \& Method: 120 elderly ASA I-III patients scheduled to undergo lower abdominal or limbs; general or orthopaedic surgery were randomly divided into two equal groups $A$ and $B$ of sixty patients. Patients were assigned into groups by lottery method. Group A patients were supposed to receive spinal block by midline approach while group $B$ patients were planned to receive spinal block by paramedian approach. Results: It was observed that success rate was significantly high in group B, $98.3 \%$ as compared to group A, $80 \%$, ( $p$ value 0.001 ). The number of attempts were significantly less in group B in comparison to group A (p-value 0.0001). Conclusion: The paramedian approach for spinal block in elderly patient's offers ease of administration and a higher success rate as compared to midline approach.
\end{abstract}

Key words: $\quad$ Elderly Patients, Midline Approach, Paramedian Approach, Spinal Block.

Article Citation: Bano N, Hayat N, Saleem S, Javed F, Rehman A, Mahmood K. Comparative study of midline versus paramedian approach of spinal block in elderly. Professional Med J 2021; 28(11):1664-1667.

https://doi.org/10.29309/TPMJ/2021.28.11.6012

\section{INTRODUCTION}

It is a day to day practice to manage elderly patients undergoing various surgical procedures. It is well known that incidence of comorbidities is quite high in geriatric population. ${ }^{1}$ General anesthesia is associated with a number of perioperative complications, while spinal block offers simple, safe and cost effective anesthetic technique. ${ }^{2,3}$ Spinal block is especially considered a safe and preferred method for elderly patients undergoing infra umblical surgical procedures. With the use of spinal anaesthesia there are less chances of intra-operative hypertension and tachycardia, less analgesic requirement in the post anaesthesia recovery room, less incidence of nausea and vomiting in $24 \mathrm{~h}$ postoperatively, and a shorter hospital stay compared with general anaesthesia. ${ }^{4}$ The technique, however is not without any risks or complications like; inadequate anesthesia, high or total spinal block, cardiac arrest, respiratory arrest, systemic toxic reaction, etc. Thus the technique of applying spinal block and experience matters to avoid such drawbacks. ${ }^{5}$

It is usually performed by midline approach. While using the midline approach at the desired level the needle passes through skin, subcutaneous tissue, supraspinous ligament, interspinous ligament ligamentum flavum, epidural space, dura mater, arachnoid mater and finally subarachnoid space. Thus a successful lumber puncture demands a thorough knowledge of anatomy, patient positioning and technique. However, despite adequate knowledge and skills, anesthetist faces challenges in certain patients like elderly due to calcification of interspinous ligaments leading to deflection of needle. ${ }^{6}$ This problem is especially faced with midline approach. ${ }^{7}$ A number of attempts may be required for administration of block using classic median approach. However, a modified technique using paramedian approach is associated with a higher success rate. ${ }^{8}$ The needle is inserted $1 \mathrm{~cm}$ lateral to midpoint and 
directed towards midline. The needle feels only the resistance of ligamentum flavum. After piercing the dura mater needle enters the subarachnoid space. Multiple attempts of spinal anesthesia occurring with midline approach are associated with patient discomfort and trauma to spine and a higher incidence of complications. ${ }^{9}$

This study was performed to compare midline approach with paramedian approach in order to assess the better approach in terms of number of attempts and success rate and.

\section{MATERIAL \& METHODS}

\section{ASA grade, inclusion and exclusion criteria}

The Randomised controlled trial was conducted in the department of anaesthesia Madina Teaching hospital, Faisalabad from Jan 2018 to Dec 2019 after approval from ethical committee (TUF/ Dean/2017/17). After written informed consent, 120 elderly ASA I-III patients undergoing various surgical procedures below umbilicus were selected. Patients with history of coagulopathy, raised intracranial pressure, skin or soft tissue infection or surgery at lumbar region, pre-existing neurological disease and allergy to Bupivacaine were excluded from study. Exclusion criteria were strictly followed. Patients were randomly divided into two groups $A$ and $B$ by using lottery method 60 patients in each group. Group A patients were supposed to receive spinal block using midline technique while group B patients were supposed to receive spinal block by paramedian approach. Detailed history and clinical examination was performed. Baseline BP heart rate, ECG, SpO2 was recorded. All patients were preloaded with Lactated Ringer@10ml/kg. Spinal block was administered by consultant anesthetist. The block was performed after complete asepsis using 25 gauge Quincke needle at L3-L4 interspace. All patients received $3 \mathrm{ml}$ of $0.5 \%$ heavy Bupivacaine. A record of success of block and number of attempts was kept. Patients were monitored throughout the procedure.

The data was analysed using SPSS version 20. Mean and standard deviation (SD) were calculated for quantitative variables like age, height, weight and number of attempts. Frequency and percentages were used for qualitative variables like gender and success of block. Independent t-test was used to compare quantitative variables like number of attempts. Chi square test was used to compare qualitative variables like success of block. P-value equal to or less than 0.05 was considered to be statistically significant.

\section{RESULTS}

The study population consisted of 120 elderly patients, 60 patients in each group A and B. Demographic variables were comparable in both groups showing no significant difference as shown in Table-I.

A higher success rate was observed with paramedian approach for spinal block. A success rate of $98.3 \%$ was observed in group B (paramedian approach) as compared to $80 \%$ in group A (midline group) which is statistically significant ( $p$-value 0.001$)$.

Lesser number of attempts were observed in paramedian group as compared to midline group (p-value 0.0001).

\begin{tabular}{|l|c|c|c|c|}
\hline \multicolumn{1}{|c|}{ Variables } & Group A & Group B & Total & P-Value \\
\hline Age (years) & $68.18 \pm 5.9$ & $69.47 \pm 6.57$ & $68.83 \pm 6.24$ & 0.262 \\
\hline Height $(\mathrm{cm})$ & $171.57 \pm 7.96$ & $170 \pm 8.8$ & $170.78 \pm 8.4$ & 0.309 \\
\hline Weight $(\mathrm{kg})$ & $74.73 \pm 9.25$ & $71.85 \pm 9.57$ & $73.29 \pm 9.5$ & 0.096 \\
\hline Gender: F & $10(16.7 \%)$ & $13(21.7 \%)$ & $23(19.2 \%)$ & 0.487 \\
\hline M & $50(83.3 \%)$ & $47(78.3 \%)$ & $97(80.8 \%)$ & 0.267 \\
\hline \multirow{2}{*}{ ASA Status: I } & $28(46.7 \%)$ & $22(36.7 \%)$ & $50(41.7 \%)$ & \multirow{2}{*}{} \\
\cline { 2 - 5 } & $32(53.3 \%)$ & $38(63.3 \%)$ & $70(58.3 \%)$ & \\
\hline
\end{tabular}




\begin{tabular}{|c|c|c|c|}
\hline \multicolumn{1}{|c|}{ Outcome } & Group A & Group B & P-Value \\
\hline $\begin{array}{c}\text { Success: No } \\
\text { Yes }\end{array}$ & $12(20.0 \%)$ & $1(1.7 \%)$ & 0.001 \\
\hline $\begin{array}{l}\text { Number of } \\
\text { attempts }\end{array}$ & $1.3 \pm 0.5$ & $1.03 \pm 0.2$ & 0.0001 \\
\hline
\end{tabular}

Table-II. Comparison of two groups for outcome.

\section{DISCUSSION}

Despite being a preferred anesthetic method for geriatric age group spinal block is not as simple as it seems to be. Age related degenerative changes, calcification of ligaments and difficult positioning pose difficulty in administration of block leading to multiple attempts and lower success rate when classic midline approach is used. ${ }^{7,10,11}$ In our study we observed a higher success rate and less number of attempts in paramedian approach as compared to midline approach. Less morbidity and increased patient comfort was achieved. In paramedian group the repeated attempts were observed in only $3.33 \%$ of patients and success rate was $98.3 \%$ as compared to $8.33 \%$ and $80 \%$ respectively in midline group. This was supported by Shehzad $\mathrm{F}$ et $\mathrm{al}^{12}$ that paramedian approach is associated with higher success rate of spinal block in elderly. The idea of paramedian approach was also supported in a study conducted by Vaishali and Sufala on one hundred elderly patients in 2015.13

Singh $\mathrm{P}$ et al ${ }^{14}$ described that placing the needle laterally in paramedian position, the anatomical limitation of the spinous process is avoided. This is of advantage in elderly patients where interspinous spaces are difficult to open up due to inadequate flexion and thus recommended paramedian approach for elderly in terms of higher success rate and lesser number of attempts. Similarly, in a study conducted by Rabinowitz $A$ and et $\mathrm{al}^{15}$ in France, it was concluded that paramedian approach is superior technique for continuous spinal block in elderly.

In addition to ease of insertion, we also observed less complications related to paramedian approach. Our observations were further supported by Batra $M$ et $\mathrm{al}^{16}$ who concluded that paramedian approach for spinal block has technical advantages and lesser complications as compared to midline approach. Contrary to this, Nisar A et al ${ }^{17}$ who studied 100 pregnant patients undergoing caesarean section under spinal block, concluded that incidence of spinal headache was higher with paramedian approach. A study conducted by Bayindir $\mathrm{S}$ and colleagues $^{5}$ in Turkey compared the early and late complications associated with median versus paramedian approach, found no statistically significant difference between the two. However, the study was not restricted to any specific age group.

In our randomized controlled trial, we found a superiority of paramedian spinal block approach over midline approach, as a higher success rate and limited number of attempts were observed with this technique.

\section{CONCLUSION}

Paramedian approach for spinal block offers a higher success rate in elderly patients as compared to midline approach. It is also associated with less number of attempts in comparison with midline approach which increases patient comfort and reduces morbidity.

Copyright $\odot 12$ Feb, 2021.

\section{REFERENCES}

1. Bhaskar SB, Bajwa SJ. From pre-operative comorbidities to post-operative cognitive dysfunction: The challenging face of geriatric anaesthesia. Indian J Anaesth. 2014; 58(3):248-250. doi:10.4103/0019-5049.135024.

2. Sohail B, Ahsanul Haq, Ameer K. Comparison of median and paramedian techniques of spinal anaesthesia. Pak Armed Forces Med J. 2011; 61 (2):199-203.

3. Islam M, Hossain M, Kabir Q, Alim A. Paramedian approach for subarachnoid blockade. A Marvellous Technique having Less Attention. JBSA. 2009; 19(1):513.

4. Impact of spinal anaesthesia vs. general anaesthesia on perioperative outcome in lumbar spine surgery: A systematic review and meta-analysis of randomised, controlled trials T. Meng1 Z. Zhong, and L. Meng. Anaesthesia 2017, 72, 391-401. doi:10.1111/ anae.13702. 
5. Bayindir S, Ozcan S, Kocyigit F, Hanbeyoglu $O$. Which approach is preferred in spinal anesthesia: Median or paramedian? Comparison of early and late complications. Istanbul Medical Journal. 2017; 18(4):205-209.

6. Crespo ME, Jones $R$. Techniques of performing paramedian approach to lumber puncture. Available at: https://www.acepnow.com/article/techniquesperforming-paramedian-approach-lumbar-puncture/. Accessed on 04/07/2020.

7. Kanagarajan M, C V, Jeeva G. Median and paramedian approach for spinal anaesthesia for caesarean delivery. A comparative analysis of safety and effectiveness. Indian Journal of Clinical Anaesthesia. $2017 ; 4(4): 518-522$.

8. Elsharkawy $\mathrm{H}$, Maheshwari A, Babazade R. Real-time ultrasound guided spinal anaesthesia in patients with predicted difficult anatomy. Minerva Anesthesiologica. 2017; 83(5):465-73.

9. Ahsan ul Haq M, Amin S, Javaid S. Paramedian technique of spinal anesthesia in elderly patients for hip fracture surgery. J Coll Physicians Surg Pak. 2005; 15(3):160-1.

10. Kallidaikurichi Srinivasan K, lohom G, Loughnane F, Lee P. Conventional landmark-guided midline versus preprocedure ultrasound-guided paramedian techniques in spinal anesthesia. Anesthesia \& Analgesia. 2015; 121(4):1089-1096.
11. Kim JH, Song SY, Kim BJ. Predicting the difficulty in performing a neuraxial blockade. Korean J Anesthesiol $2011 ; 61(5): 377-81$.

12. Shehzad F, Haider S, Zafar B. Comparison of paramedian with midline technique of spinal anaesthesia in elderly. Pak Armed Forces Med J. 2018; 68(5):1168-72.

13. Bapat $V$, Vishwasrao S. Spinal anaesthesia with midline and paramedian technique in elderly patients. Indian journal of applied research. 2015; 5(9):442-444.

14. Singh P, Agrawal S, Dwivedi S, Yadav A. A comparative evaluation between median and paramedian approaches for sub-arachnoid block in elderly patients. International Journal of Research in Medical Sciences 2016; :2069-2072.

15. Rabinowitz A, Bourdet B, Minville V, Chassery C, Pianezza A, Colombani $A$ et al. The paramedian technique: A superior initial approach to continuous spinal anesthesia in the elderly. Anesthesia \& Analgesia. 2007; 105(6):1855-1857.

16. Batra $M$, Saraf $S$, Khan $P$ et al. Advantages of the paramedian approach for lumbar spinal analgesia. A clinical comparison between midline and paramedian approaches. European journal of biomedical and pharmaceutical sciences. 2016; 3(2):442-445.

17. Nisar A, Saleem J, Hussain S, Bashir K. Comparison of postdural puncture headache in median and paramedian approach under spinal anaesthesia in caesarean section. P J M H S. 2016; 10(1):298-301.

\begin{tabular}{|c|l|l|l|}
\hline \multicolumn{3}{|c}{ AUTHORSHIP AND CONTRIBUTION DECLARATION } \\
\hline No. & \multicolumn{1}{|c|}{ Author(s) Full Name } & \multicolumn{1}{|c|}{ Contribution to the paper } & Author(s) Signature \\
\hline 1 & Nadia Bano & Manuscript writing. \\
\hline 2 & Nazim Hayat & Data collections to analysis. \\
\hline 3 & Saira Saleem & Review of literature. \\
\hline 5 & Farhan Javed & References. \\
\hline 6 & Khalid Mahmood & Review / References. \\
\hline
\end{tabular}

